\title{
THE EFFECT OF TRANSIENT LIQUID PHASE ON THE JOINING PROCESS OF ALUMINUM FOAM CORE SANDWICHES
}

\author{
A. T. Tabrizi, M. Azadbeh
}

\begin{abstract}
Despite recent developments in sandwich panels production technology, there are some difficulties in joining core sandwiches. Liquid Phase Sintering is a conventional method to increase the density of powder metallurgy parts. In this paper, we applied LPS as a joining process between Al-foam and Al-metal by using Al-mixture powders with different compositions as the interlayer. At first stage, Al-Zn powder mixture was used and the possibility of this process was investigated. At later stages, we tried to increase the joint bonding strength with different Al-mixture powder compositions. 3-point bending test was applied and by using mathematical relations, bonding strengths were calculated. The highest bonding strength was obtained, about $9 \mathrm{kPa}$, when Al-Zn-Mg was used as the interlayer. Also energy dispersive spectrometry (EDS) was used to investigate the diffusion of additive elemental powders to Al-mixture powders.
\end{abstract}

Keywords: Aluminum foam, Liquid phase sintering, Al-powder alloy, Bonding Strength

\section{INTRODUCTION}

Metallic foam is a class of materials with novel mechanical, thermal, electrical and acoustic properties that are, as of yet, imperfectly developed and characterized [1,2]. Metallic foams and foam sandwich structures possess increasing use, e.g. as a lightweight structural members in automotive industry [3], space applications [4], heat exchangers [5], fluid filters and catalyst supports [6]. This leads to production of difference metallic foams such as aluminum [7-9], nickel [10, 11], steel [12-14], titanium $[15,16]$, etc. Aluminum foam is a type of metallic foam that can offer a unique combination of several (apparently contradictory) properties, which cannot be obtained with conventional materials (e.g., ultra-low density, high stiffness, the ability to absorb crash energy, low thermal conductivity, low magnetic permeability, and good vibration damping) $[17,18]$. Due to their ultra-low density combined with their excellent mechanical properties, aluminum foams have roused much interest [19]. In combination with new constructional principles, aluminum foams could replace conventional stamped steel parts and lead to significant weight reductions. In the aerospace industry, finding solutions to reduce the weight of planes is an intense topic of study that will mean less required fuel and lower costs. Clearly, using aluminum foams can, not only bring huge economic benefits, but can also save many resources and energy if aluminum foams can successfully be applied to aircraft manufacturing [20]. Currently, aluminum foams can be manufactured in a variety of ways, such as solid-gas eutectic solidification, casting [21,22], powder metallurgy routes $[17, \underline{23}]$ and space holder technique [24]. In terms of existing 
techniques and new technologies to produce aluminum foam sandwiches (AFS) $[25,26]$, it is difficult to attain large aluminum foam products and complicated structures which are key obstacles in expanding the real applications of aluminum foams. One alternative is to join aluminum foams with other foams to form an integrated structure, or other materials like sheets in sandwich panels, in which welding and industrial adhesives are the primary methods used. However, because of the characteristics of the fusion welding process itself, the collapse of the foam structure is unavoidable. Additionally, welding with pressure, such as ultrasonic torsion welding, pressure welding, and diffusion welding will likely cause unacceptable deformation. A collapsed foam structure and deformation will have significantly negative effects on the mechanical properties of aluminum foams [20]. Bonding by adhesives [27-32] or solders or even mechanical fasteners $[27,33]$ have been used in most metal honeycomb and sandwich panels' structures. In this case, the bonding strength of adhesives dominates the mechanical properties of the honeycomb structures [34]. Though the adhesive bonding process is superior for low temperature applications, the expansion in the high temperature region is limited $[35,36]$. Also other joining techniques were studied, like spark plasma sintering [37], diffusion bonding [35], soldering [20], and brazing [10].

As is mentioned, one of the foam production routes is powder metallurgical sintering. Al foams have been successfully made by sintering and dissolution process (SDP) solid state sintering. It has long been known that the formation of a liquid phase during sintering can significantly accelerate mass transport due to the formation of transient liquid phase [38]. Liquid phase sintering has become a more universally applied process and over $70 \%$ of sintered products in the powder metallurgy industry are manufactured by this route $[2,39]$.

So the purpose of this research work is to study the feasibility of using as a foam production route, liquid phase sinteringas the joining process of aluminum foam to aluminum metal in aluminum foam core sandwiches and optimizing the bonding strength.

\section{MATERIALS AND METHODS}

During this investigation, closed-cell aluminum foam was used, which was produced by the blowing agent method at Net Foam Co. in Mashhad, Iran. The chemical composition of the foam was $\mathrm{Al}-\mathrm{Si}$, and the porosity was approximately $85 \%$. These foam blocks were cut to dimensions $50 \mathrm{~mm} \times 25 \mathrm{~mm} \times 10 \mathrm{~mm}$ by wire cut. The commercial pure aluminum plate was used and was cut to dimensions $50 \mathrm{~mm} \times 25 \mathrm{~mm} \times 1 \mathrm{~mm}$. Based on data in the literature $[40,41] \mathrm{Al}-\mathrm{Zn}$ system was chosen to be added to assembly as a powder interlayer. Three types of aluminum-zinc mixture powder were used. The weight percents of mixtures are shown in Table 1. These mixtures were weighted by high accurate digital scale and were prepared by mechanical mixing. The used raw powders are listed below:

- Air atomized aluminum (Al) powder, with $99.7 \%$ purity and average particle size of $60 \mu \mathrm{m}$ supplied by Merck

- Zinc, Zn, with $99.6 \%$ purity and maximum size of $100 \mu \mathrm{m}$ supplied by Merck

- Magnesium, Mg, with $99.8 \%$ purity and maximum particle size of $50 \mu \mathrm{m}$ supplied by Merck

- Copper, $\mathrm{Cu}$, with $99.0 \%$ purity and maximum particle size of $50 \mu \mathrm{m}$ supplied by Merck 
Tab.1. Chemical Composition of Al-mixture powder alloy in weight percent

\begin{tabular}{|c|c|c|c|c|}
\hline Sample Number & $\mathrm{Al}$ & $\mathrm{Zn}$ & $\mathrm{Mg}$ & $\mathrm{Cu}$ \\
\hline $\mathrm{AZ}$ & 94.5 & 5.5 & - & - \\
\hline AZM & 92 & 5.5 & 2.5 & - \\
\hline AZMC & 90.25 & 5.5 & 2.5 & 1.75 \\
\hline
\end{tabular}

Before sintering process, surface preparation treatment was applied to remove the oxide layer from the boding surfaces of foams and plates. First, the joining surface of the plates was ground by brush, and the joining surfaces of foams were ground by $\mathrm{SiC}$ abrasion paper and then both were washed in acetone in an ultrasonic apparatus for 10 minutes.

After preparing the bonding surfaces, the mixtures of powders were spread on them and the whole assemblies were sintered at $610^{\circ} \mathrm{C}$ for 30 minutes nominal in flowing inert atmosphere $\left(\mathrm{N}_{2}-99.99 \%\right.$ purity-flow rate $\left.2 \mathrm{~min}^{-1}\right)$ in a tube furnace. The schematic of the process is shown in Figure 1. A minimum of three samples were tested for each powder interlayer to ensure data reproducibility.

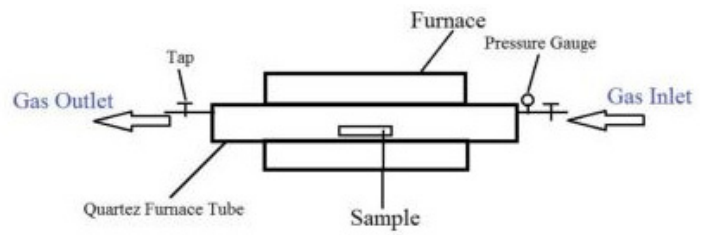

Fig.1. Schematic of LP-Sintering.

The micro-structural and chemical compositions of the joints were examined using a Scanning Electron Microscope (SEM) equipped with an Energy Dispersive Spectrometer (EDS). The joints were sectioned across the interface zone for studying the micro-structural characterization. The 3-point bending test was performed, schematically shown in Figure 2, to determine the bonding strength of the joints by using a universal testing machine at room temperature $[\underline{42,43}]$.

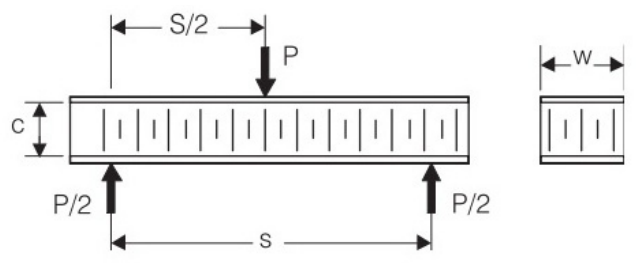

Fig.2. Schematic of 3-Point Bending Test [42].

\section{RESULTS AND DISCUSSION}

First usual step of examination of welded or joined parts is visual testing. The macroscopic overviews of the bonded joints, which are shown in Figure 3, were conducted through visual observation. Unlike the other joining processes like fusion welding, pressure welding and diffusion bonding [20], no visible macroscopic deformation and foam structure collapse can be observed in the macroscopic image of joints. Just thickness decrease in the upper bonding surface was seen, which was due to the pressure, which was applied during 
the liquid phase sintering for improving $\mathrm{Al}$ powder sintering. Sintering of aluminum is complicated due to the presence of a thermodynamically stable oxide layer $\left(\mathrm{Al}_{2} \mathrm{O}_{3}\right)$ that covers the $\mathrm{Al}$ particles. The pressure was applied to break this oxide layer on the particles in AZ, but in samples AZM \& AZMC. With adding Mg particles to the powder mixture, pressure was not applied. According to the Ellingham diagrams, at the constant temperature of $610^{\circ} \mathrm{C}, \mathrm{Mg}$ is more likely to react with oxygen than $\mathrm{Al}$, so $\mathrm{Mg}$ was added to the powder mixtures with the aim of reacting with oxygen and destroying the oxide layer on the $\mathrm{Al}$ particles and convening the sintering process of $\mathrm{Al}$. The possible reaction is:

$3 \mathrm{Mg}+4 \mathrm{Al}_{2} \mathrm{O}_{3}=3 \mathrm{MgAl}_{2} \mathrm{O}_{4}+2 \mathrm{Al}$

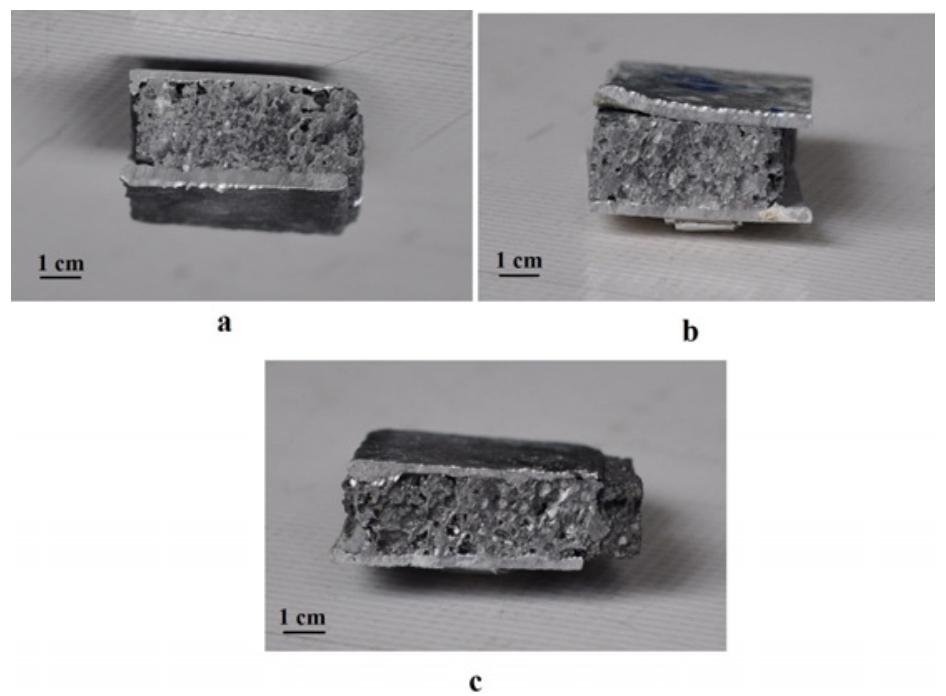

Fig.3. Macroscopic image of joints, a. AZ, b. AZM, c. AZMC.

The Al-Zn system, which is presented in Figure 4, shows some of the characteristics of an ideal liquid phase sintering system where zinc has a lower melting point than aluminum; no intermediate phases form and there is complete miscibility in the liquid [41]. However, the solid solubility ratio is non-ideal. The maximum solid solubility of zinc in aluminum is $83.1 \%$, while the maximum solid solubility of aluminum in zinc is $1.2 \%$. The liquid phase during sintering of $\mathrm{Al}$ with $\mathrm{Zn}$ is therefore highly transient and sintering of Al-Zn alloys is an extremely sensitive process. Furthermore, the liquid must wet the solid and give a high diffusion rate for the solid. Wet-ability and spreading of liquid are two important factors. Capillary forces which are caused from the superficial porosities in the foam are the important factor that guide towards formation of a dense, uniform and continues bonding layer in joining treatments, which include a transient liquid phase, like liquid phase sintering and soldering. According to the phase diagram of Al-Zn, Al-Mg and $\mathrm{Al}-\mathrm{Cu}$ [44], the alloying elements react with $\mathrm{Al}$ to form a eutectic liquid at 381, 450 and $548{ }^{\circ} \mathrm{C}$ respectively. Beside these eutectics, Martin et al. [45] have reported the formation of a liquid between $\mathrm{Mg}_{17} \mathrm{Al}_{12}$ at about $437{ }^{\circ} \mathrm{C}$. In other words, contact between adjacent particles of $\mathrm{Mg}$ and $\mathrm{Al}$ could cause low melting phases. Also, in Figure 5, a bonding layer can be observed in some regions of the bonding interface which directly confirms a satisfactory wetting process, but partial spreading of the liquids. This partial spreading of liquid phase is due to the superficial porosity on the bonding surface of $\mathrm{Al}$ foam, which was acting like a barrier to the spreading of liquid phase. 

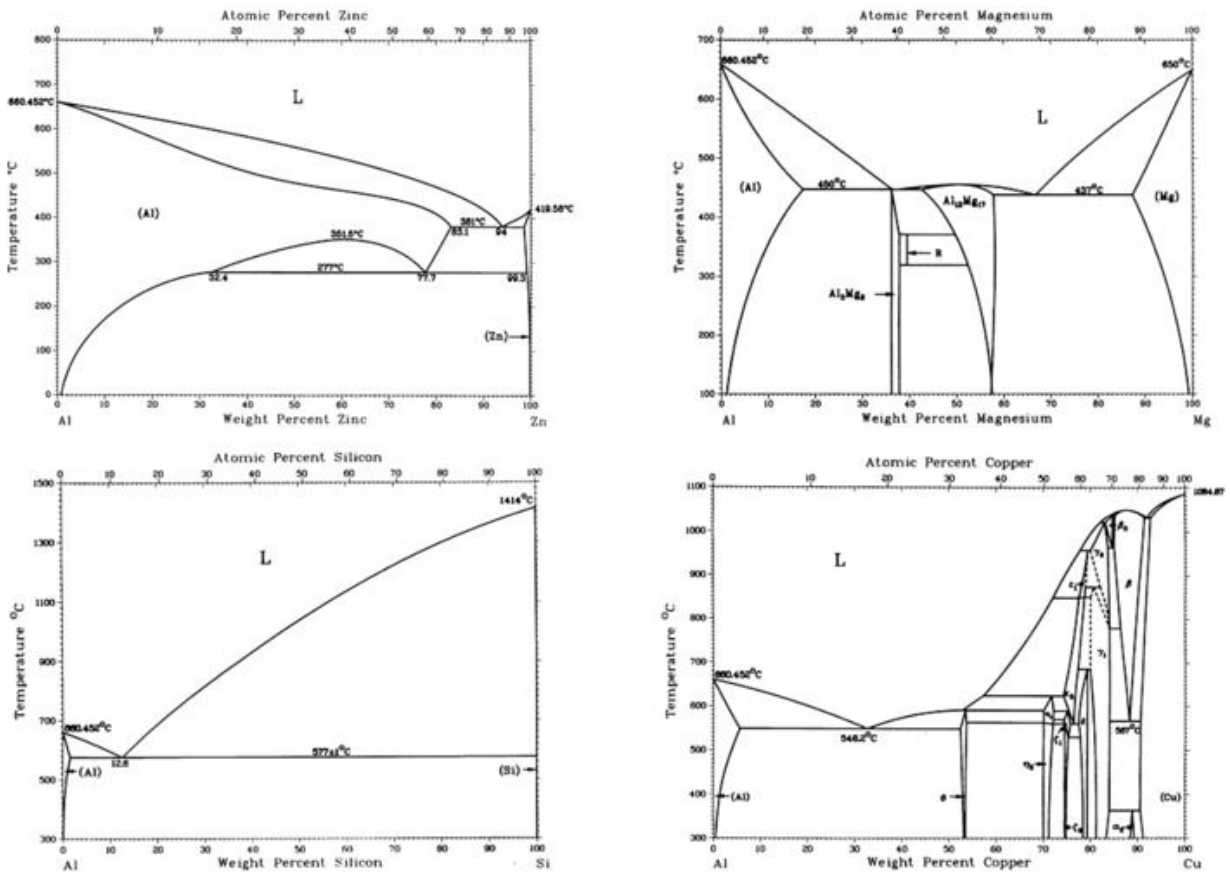

Fig.4. Al-X Phase Diagrams [44].
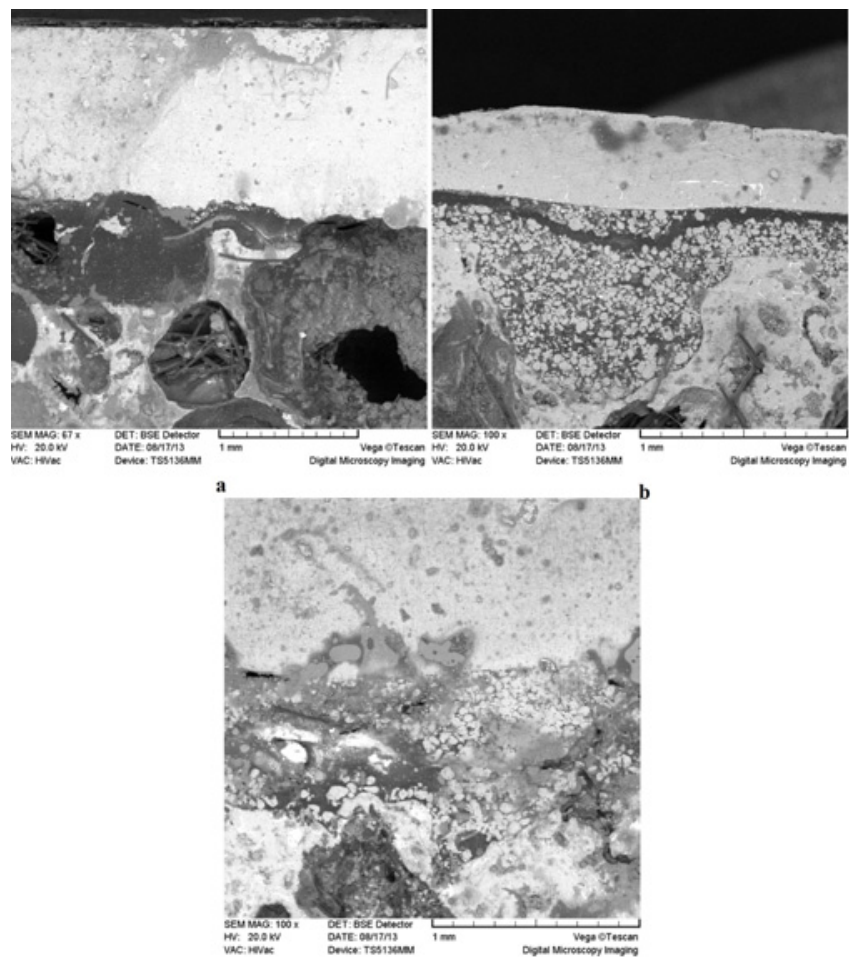

Fig.5. Foaming zone of the joints, a. AZ, b. AZM, c. AZMC. 
In SE microscopic images of the joints shown in Figure 5; a narrow foam zone which was formed during liquid phase sintering can be observed, which is avoiding the sharp variation of the bulk material to cellular material. The high vapour pressure of $\mathrm{Zn}$ also gives a rise to additional porosity at the interface. This can improve the mechanical properties of the joint. The results of 3-point bending test confirmed this claim.

The joining process during sandwich fabrication is a most difficult process, which requires strict quality control. In addition, the failure modes of sandwich panels, which are categorized into face yielding and fracture, core shear and crimping, face wrinkling and dimpling, and overall buckling, are closely related to adhesion characteristics between the face and core of the sandwich structures [28]. For measuring shear strength of the joint, 3point bending test was applied to the samples and equation 1 was used to calculate the bonding strength [42]. The bending strain curves are shown in Figure 6. The bonding strengths of the joints are presented in Table 2.

$$
\tau=\frac{P}{2 \omega W}
$$

where, $\tau$ is considered as the bonding strength, $\mathrm{P}$ is total load, $\mathrm{c}$ is core thickness, which is constant $(10 \mathrm{~mm})$ and $\mathrm{w}$ is the width of the panel.

Tab.2. Results of 3-Point Bending Test \& Calculated Bonding Strength.

\begin{tabular}{|c|c|c|c|}
\hline Sample & $\begin{array}{c}\text { Elongation } \\
{[\%]}\end{array}$ & $\begin{array}{c}\text { Ultimate Bending Strength } \\
{[\mathrm{MPa}]}\end{array}$ & $\begin{array}{c}\text { Bonding Strength } \\
{[\mathrm{KPa}]}\end{array}$ \\
\hline AZ & 13.5 & 240 & 4.8 \\
\hline AZM & 11 & 450 & 9 \\
\hline AZMC & 9 & 200 & 4 \\
\hline
\end{tabular}

These curves are extensive, which indicates a high absorbing energy material. This is due to the absence of intermetallic compound formation during joining in Al-mixture powders. All samples have shown elastic behaviour at small strains, but AZM has more formability than the other samples before the yield point, also after that, the samples are work hardened during application of the load, and failure was observed only on the bottom surface, which is under tensile stress. From the results of Table 2, it is obvious that AZM has the higher bonding strength.

The fracture surfaces were studied with SEM microscopy. In Figure 7, the liquid phase was clear and was shown in the picture. The fracture surface obtained from 3-point bending test samples gives a good reference to the corresponding properties achieved, in consequence, of pore elimination with formation of liquid phase. It is obvious that the amount of the liquid phase, which was formed during the sintering was not enough in AZMC, and this lack of the liquid phase in AZMC is caused the lower bonding strength of the joint due to the pores. Also the presence of the $\mathrm{Cu}$ powder into the interlayer powder mixture and the diffusion of that during the sintering partially compensate the lack of the liquid phase. It is clearly visible that the first indication of liquid phase formation is found in presence of additive $\mathrm{Zn}$ powder in the samples. Evidently, the aluminum grains have been surrounded by a light phase which is the trace of the liquid phase. When comparing the fracture surfaces of samples sintered with different additive powders, it is clear that the AZM exhibits the more solidified liquid phase than AZ. But the AZMC exhibits less and inadequate liquid phase which is a main reason of low bonding strength of AZMC in comparison with other samples. The fracture surface of AZM differs from AZ insofar as the aluminum powder particles are no more visible than AZ, which can be regarded as an 
indicator for sufficient liquid phase formation and spreading along aluminum inter particle regions.

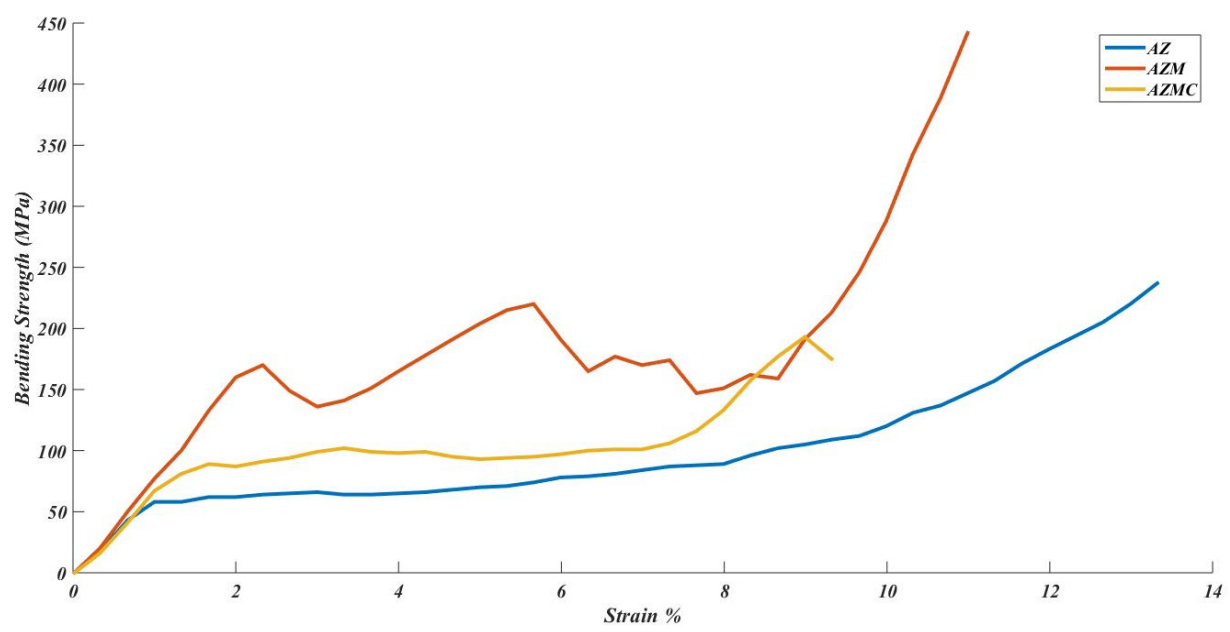

Fig.6. Bending Curves of Samples.

An interesting variant to traditional liquid phase sintering involves a transient liquid which solidifies by diffusional homogenization during sintering. The transient liquid forms between mixed ingredients during heating to the sintering temperature. Unlike persistent liquid phase sintering, the liquid has a high solubility in the solid and disappears with sintering time. By studying the EDS diagram of samples, Figure 8, 9 and 10, it is obvious that $\mathrm{Zn}$ powder diffused to the foam and plate uniformly. This uniform diffusion of $\mathrm{Zn}$ powder is because of the miscibility of $\mathrm{Zn}$ in $\mathrm{Al}(83.1 \%)$, and indicates that $\mathrm{Zn}$ played its role well enough to produce liquid phase and spread through the interface. Furthermore, $\mathrm{Cu}$ powders have the same condition in AZMC, which is shown in Figure 10. However, the variations of the $\mathrm{Mg}$ (Figure 9) and $\mathrm{Si}$ are interesting at the interface. The source of $\mathrm{Si}$ is the impurity in the initial composition of the $\mathrm{Al}$ foam. The diffusion of $\mathrm{Si}$ is due to the eutectic of $\mathrm{Al}-\mathrm{Si}$, which was formed at $577^{\circ} \mathrm{C}$. The presence of liquid phase of $\mathrm{Si}$ above this temperature, prepared the persistent liquid phase during sintering, which helped to diffuse particles and form metallurgical bonding at the interfaces. 


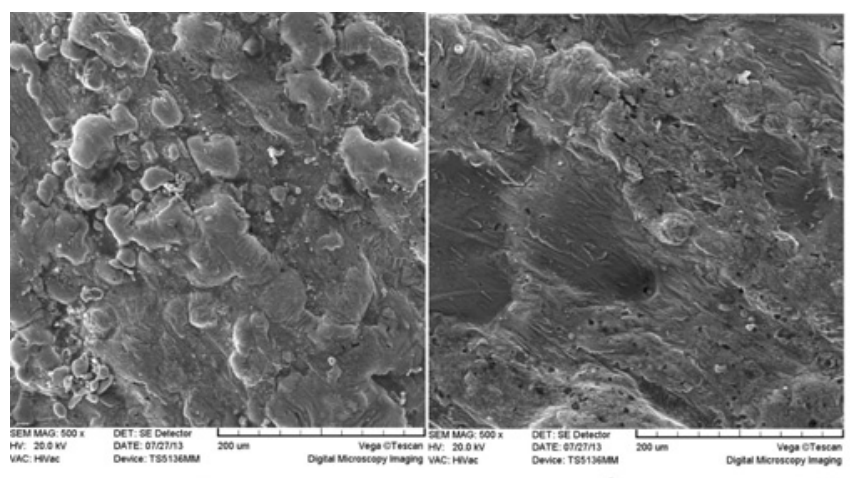

a

b
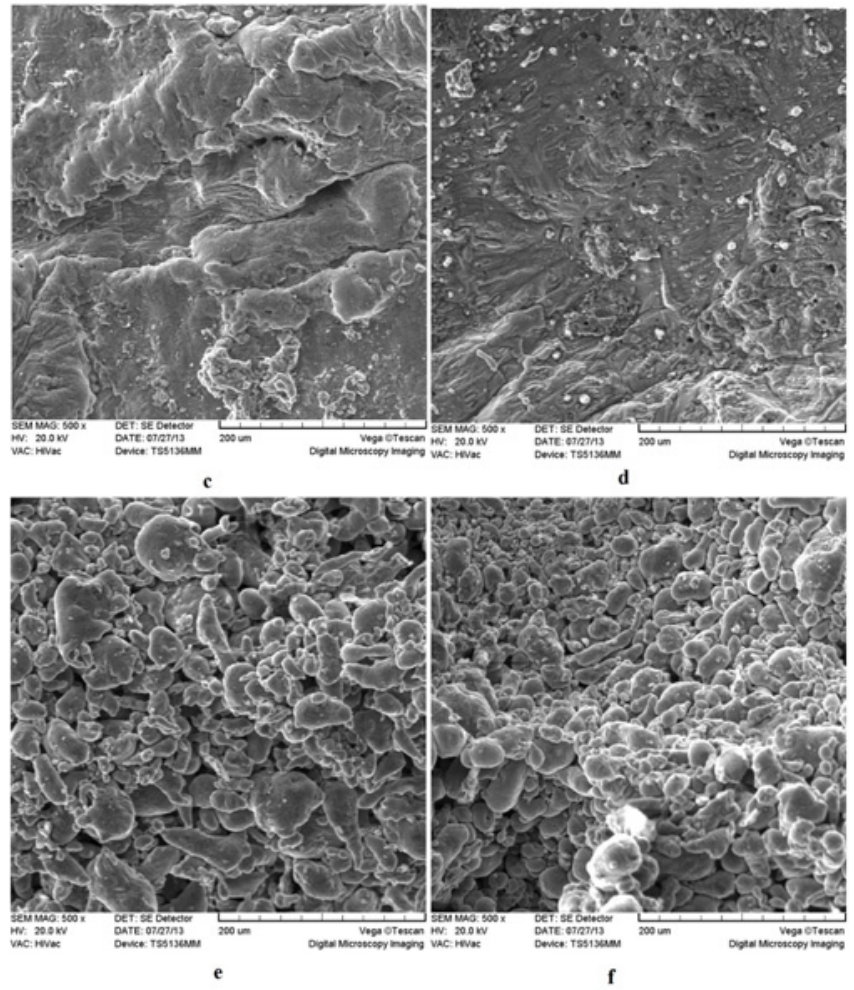

Fig.7. The fracture surfaces of bonding surfaces, a. the upper bonding surface of AZ, b. the bottom bonding surface of AZ, c. the upper bonding surface of AZM, d. the bottom bonding surface of AZM, e. the upper bonding surface of AZMC, f. the bottom bonding surface of AZMC. 

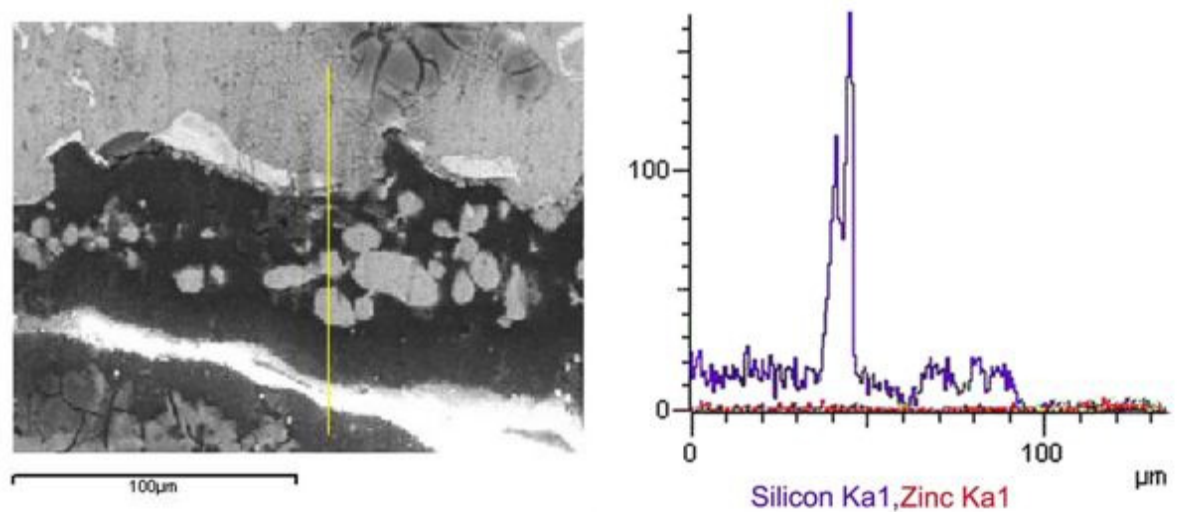

Fig.8. EDS of the AZ.

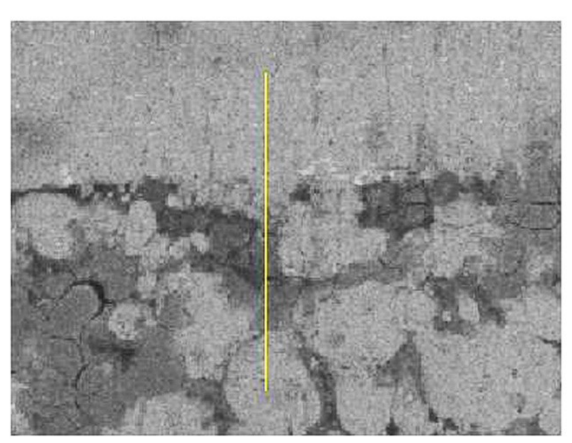

$100 \mu m$

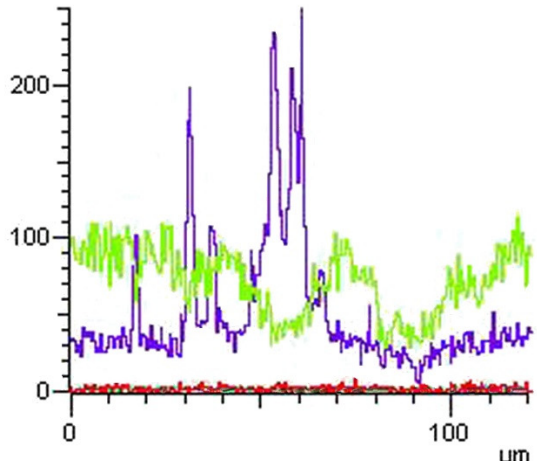

Silicon Ka1,Magnesium Ka1-2, Zinc Ka1

Fig.9. EDS of the AZM.

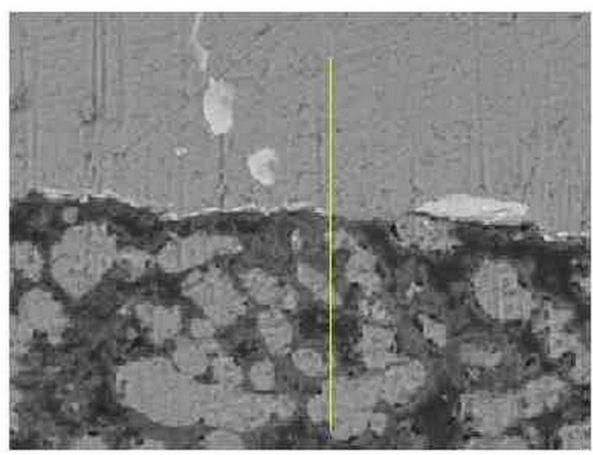

$100 \mu \mathrm{m}$

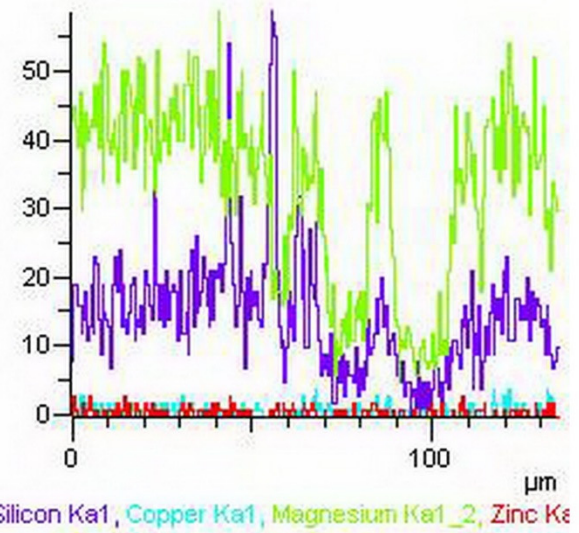

Fig.10. EDS of the AZMC. 
The liquid of $\mathrm{Si}$ is viscous; thus it helps to spread the liquid phase along the bonding surface. By comparison of diagrams, it can be concluded that the amount of the elements which diffused to the interface in AZM is more than in the two other samples. And also by comparison of the variation of $\mathrm{Mg}$ in diagrams (Figure 9 and 10), it can be concluded that the liquid phase in AZM was steadier than the liquid phase in $A Z$ and AZMC, which were prepared to diffuse more elements of the bonding region.

\section{CONCLUSION}

The joining of the $\mathrm{Al}$ foam to the plate was done successfully through the liquid phase sintering using the $\mathrm{Al}$ mixture powders as an interlayer. The bonding strength was about $9 \mathrm{kPa}$ for sample Al-Zn-Mg mixture powder and $4.8 \mathrm{kPa}$ for $\mathrm{Al}-\mathrm{Zn}$ and $4 \mathrm{kPa} \mathrm{Al}-\mathrm{Zn}-$ $\mathrm{Mg}-\mathrm{Cu}$. The amount of the liquid phase in $\mathrm{Al}-\mathrm{Zn}-\mathrm{Mg}-\mathrm{Cu}$ sample was not enough and caused the lower bonding strength. From the EDS diagrams and the amount of the diffused powders, it is obvious that the better conditions were prepared during the sintering when $\mathrm{Al}-\mathrm{Zn}-\mathrm{Mg}$ powders were used, and both $\mathrm{Zn}$ and $\mathrm{Mg}$ particles had played their role well during the sintering process. Zn particles prepared enough liquid phase and $\mathrm{Mg}$ particles prevented oxidizing the Al particles. Also the SEM images of fracture surfaces confirmed that the amount of liquid phases was not enough in AZMC, which was caused by the nonequilibrium heating and retarted the formation of eutectic liquid phases and the expected influence of $\mathrm{Cu}$ particles, increasing the joint strength, was not observed. Also the diffusion of Si was observed in samples which is due to the initial composition of the Al-foam and melting point of eutectic Al-Si.

\section{REFERENCES}

[1] Degischer, HP., Kriszt, B.: Handbook of Cellular Metals, Production, Processing, Applications. Wiley-VCH, 2002

[2] Zhao, Y., Han, F., Fung, T.: Materials Science and Engineering A, vol. 364, 2004, p. 117

[3] Ermolaeva, NS., Castro, MBG., Kandachar, PV.: Materials \& Design, vol. 25, 2004, p. 689

[4] Schwingel, D., Seeliger, HW., Vecchionacci, C., Alwes, D., Ditrich, J.: Acta Astronautica, vol. 61, 2007, p. 326

[5] Odabaee, M., Hooman, K.: Applied Thermal Engineering, vol. 36, 2012, p. 456

[6] Brothers, AH., Dunand, DC.: Scripta Materialia, vol. 54, 2006, p. 513

[7] Stobener, K., Baumeister, J., Rausch, G., Busse, M.: Forming metal foams by simpler methods for cheaper solutions. Elsevier Ltd., 2005

[8] Li, YG., Wei, YH., Hou, LF., Guo, CL., Yang, SQ.: Journal of Alloy and Compounds, vol. 649, 2015, p. 76

[9] Duarte, I., Ventura, E., Olhero, S., Ferreira, JMF.: Materials Letters, vol. 160, 2015, p. 162

[10] Jarvis, T., Vioce, W., Goodall, R.: Materials Science and Engineering A, vol. 528, 2011, p. 2592

[11] Tang, T., Li, K., Shen, Z., Sun, T., Wang, Y., Jia, J.: Journal of Power Source, vol. 301, 2016, p. 54

[12] Mondal, DP., Jain, H., Das, S., Jha, AK.: Materials \& Design, vol. 88, 2015, p. 430

[13] Bakan, HI., Korkmaz, K.: Materials \& Design, vol. 83, 2015, p. 154

[14] Kaya, AC., Fleck, C.: Materials Science and Engineering A, vol. 615, 2014, p. 447

[15] Aguilar, C., Guerra, C., Lascano, S., Guzman, D., Rojas, PA., Thirumurugan, M., Bejar, L., Medina, A.: Materials Science and Engineering C, vol. 58, 2016, p. 420 
[16] Mondal, DP., Patel, M., Jain, H., Jha, AK., Das, S., Dasgupta, R.: Materials Science and Engineering A, vol. 625, 2015, p. 331

[17] Neville, BP., Rabiei, A.: Materials and Design, vol. 29, 2008, p. 388

[18] Lehmhus, D., Banhart, J.: Materials Science and Engineering A, vol. 349, 2003, p. 98

[19] Wang, H., Yang, D., He, S., He, D.: J. Materials Science Technology, vol. 26, 2010, no. 5 , p. 423

[20] Huang, Y., Gong, J., Lv, S., Leng, J., Li, Y.: Materials Science and Engineering A, 2012

[21] Vendra, LJ., Rabiei, A.: Materials Science and Engineering A, vol. 465, 2007, p. 59

[22] Weirauch Jr., DA.: Current Opinion in Solid State and Materials Science, vol. 9, 2005, p. 230

[23] Alizadeh, M., Paydar, MH.: Materials \& Design, vol. 30, 2009, p. 82

[24] Bafti, H., Habibolahzadeh, A.: Materials and Design, vol. 31, 2010, p. 4122

[25] Contorno, D., Ficile, L., Fratini, L., Micari, F.: Journal of Materials Processing Technology, vol. 177, 2006, p. 364

[26] Chung, HJ., Rhee, KY., Lee, B., Lee, JH.: Journal of Alloys and Compounds, vol. 481, 2009, p. 214

[27] Oluran, OB., Fleck, NA., Ashby, MF.: Journal of Material Science, vol. 35, 2000, p. 1079

[28] Lee, CS., Lee, DG., Oh, JH.: Composite Structures, vol. 66, 2004, p. 231

[29] Taskin, V., Urkmez Taskin, N., Demihan, PA., Sahin, A. In: $16^{\text {th }}$ international conference on composite structures. Porto, 2011

[30] Chung, HJ., Rhee, KY., Han, BS., Ryu, YM.: Journal of Alloys and Compounds, vol. 459, 2008, p. 196

[31] Huber, O., Klaus, H.: Materials Letters, vol. 63, 2009, p. 1117

[32] Yoon, SH., Lee, DG.: Composite Structures, vol. 94, 2011, p. 102

[33] Pickin, CG., Young, K., Tuersley, I.: Materials and Design, vol. 28, 2007, p. 2361

[34] Burlayenko, VN., Sadowski, T.: Composite Structures, vol. 92, 2010, p. 2890

[35] Kitazono, K., Kitajima, A., Sato, E., Matsushita, J., Kuribayashi, K.: Materials Science and Engineering A, vol. 327, 2002, p. 128

[36] Bozhevolnaya, E., Lyckegaard, A., Thomsen, OT.: Composites: Part B, vol. 39, 2008, p. 185

[37] Ko, YH., Chung, SH., Oh, IH., Cho, JI., Kang, CS.: Advanced Materials Research, vol. 8, 2007, p. 1394

[38] German, RM.: Liquid Phase Sintering. Plenum Press, 1985

[39] Mustapha, F., Mustapha, M., Noorsal, K., Mamat, O., Hussain, P., Ahmad, F., Muhamad, N., Haris, SM.: Journal of Materials Processing Technology, vol. 210, 2010, p. 1598

[40] Schaffer, GB., Sercombe, TB., Lumley, RN.: Materials Chemistry and Physics, vol. 67, 2001, p. 85

[41] Martin, JM., Castro, F.: Journal of Materials Processing Technology, vol. 143-144, 2003, p. 814

[42] Mechanical Testing of Sandwich Panels. Technical Notes. Hexcel Composites, Publication LTU035b; March 2007

[43] Rao, KK., Rao, KJ., Sarwade, AG., Chandra, MS.: International Journal of Engineering Research and Applications, vol. 2, 2012, p. 365

[44] Alloy Phase Diagrams. ASM Handbook. Vol. 3. Materials Park, OH : ASM International, 1992

[45] Martin, JM., Gomez-Acebe, T., Castro, F.: Powder Metallurgy, vol. 45, 2002, p. 173 